\title{
Utilization of NVIS HF Radio as Alternative Technologies in Rural Area of North Maluku
}

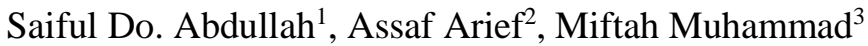 \\ Department of Informatic Engineering \\ Universitas Khairun \\ Ternate-Indonesia \\ ${ }^{1}$ saifulabdullah12@gmail.com, ${ }^{2}$ assaf.arief@unkhair.ac.id, ${ }^{3}$ miftahmuh@unkhair.ac.id
}

\begin{abstract}
This study is still an initiation stage for implementation in Northern Maluku Archipelago. Because of the characteristics of the archipelago and many black spots in the rural area. An alternative research is conducted to overcome technical problems in rural areas of the archipelagoes. One of the alternative technologies is using of $\mathrm{HF}$ (High Frequency) radio waves which are working at a frequency of 3 to $30 \mathrm{MHz}$, it's used for long-distance radio communication due to the nature of its waves can be reflected by the ionosphere, the airwaves () emitted, depending on the frequency, timing and conditions of the ionosphere, HF radio communication NVIS (Near Vertical Incident skywave) able to cope with the skip zone so as not to affect the quality of emission, whether grasslands, dense forests, mountain slopes etc. The methodology is using ITURHFProp software, there are two parts of sub-programs, namely P533 () and ITURHFProp (). Link Budget is a power budget estimated that needs to be taken into account to ensure that the acceptance level is well received. Link budget calculation has an important role so that the communication network design can achieve optimum and efficient results both in terms of technical reliability and in terms of cost. NVIS is a reflection of the times by a layer of F / F2 ionosphere, the beam (signal) HF radio for communication with the emitting angle almost perpendicular beam (Near Vertical) upon approaching $\mathbf{9 0}^{\circ}$. The reflections results have varied angles, with coverage communication distance up to $300 \mathrm{~km}$.
\end{abstract}

Keyword-ITURHFProp; NVIS HF; link budget; rural area; North Maluku Archipelago

\section{INTRODUCTION}

HF (High Frequency) radio is the communication of radio waves whose wavelengths range from 10 to 100 meters, and work at frequencies between 3 to $30 \mathrm{MHz}$, usually used for long distance radio communication because of their wave properties which can be reflected by ionospheres layers. Space waves (skywave) are emitted, depending on the frequency, time and condition of the ionosphere [1][11]. Propagation (skywave) is reflected by an ionospheres layer consisting of several layers ranging from 50 to $400 \mathrm{~km}$ above the earth's surface, ionospheres waves emitted from a transmitter antenna in one direction which produces a certain angle with reference to the earth's surface.
HF NVIS radio communication is able to emit with the angle of emission (Take off or Elevation Angle) which is almost perpendicular (near vertical), so that the signal reflected by the ionospheres layer falls back to the area that is about $0-400 \mathrm{Km}$ from the origin of the emission [1]

NVIS refers to the radio propagation mode which involves the usage of an antenna with a very high radiation angle, approaching or reaching 90 degrees (straight up) along with the selection of frequencies just below the critical frequency, to build reliable communications over a $0-200$ mil radius or more, give or take 100 miles [2][3]. Previous HF NVIS radio communication in the early 90s at the international level, Patricia Gibbons (WA6UBE) socialized NVIS in an amateur environment, and in 1995 Major Edward J. Farmer (AA6ZM) presented his article (NVIS: Near Vertical Incidence).

Indonesia as an archipelago with many volcanoes along the world's largest volcano slab line is very vulnerable to natural disasters. More specifically, the archipelago in North Maluku, which has nearly 13,000 large and small islands, almost $70 \%$ of which are rural areas. On the island of Java since July 2006 the use of HF ANVIS radio has been consciously used for alternative communication after natural disasters and earthquakes. Alternative technology is very important to be used in black spot areas on islands that have not had adequate network infrastructure. Like the fact that happened in rural areas in the islands of North Maluku, due to inequality of development between the islands of Java and non-Java.

This study is still an initiation stage for implementation on the islands of North Maluku. Because of the characteristics of the archipelago and many black spots in rural areas. An alternative study was conducted to address technical problems in rural areas on the islands. Like almost $70 \%$ of the rural areas in the North-Maluku Islands do not have standard and adequate infrastructure so that alternative technologies are needed for emergency communication problems and early disaster mitigation in order to quickly address the problem of human life safety after a disaster occurs. One of the alternative technologies is used HF (High Frequency) radio wave. 


\section{LITERATURE REVIEW}

\section{A. Data Communications}

Definition of data communication is the process of sending data related to the transmission of signals that are efficient and reliable (reliable). Includes signal transmission, transmission media, signal coding, interfacing between layers, data link control, and multiplexing [5][6].

The basic usage of this communication system is running data exchanges between 2 parties. In Figure 2.1 a special example is shown, which is communication between a workstation and a server connected to a public telephone network. Another example is the exchange of voice signal signals between 2 phones on the same network. Following are the key elements of the model [7]:

- Source (source): This tool generates data so that it can be transmitted, for example, telephone and PC (Personal Computer).

- Transmitter (sender): Usually data generated from the source system is not transmitted directly in its original form. A transmitter simply moves and marks information in the same way as it that can be transmitted over several sequential transmission systems.

- Transmission System: In the form of a single transmission line or complex network that connects the source with a destination.

- Receiver: Receiver receives signals from the transmission system and combines them into certain forms that can be captured by the destination.

- Destination: Capture data generated by the receiver.
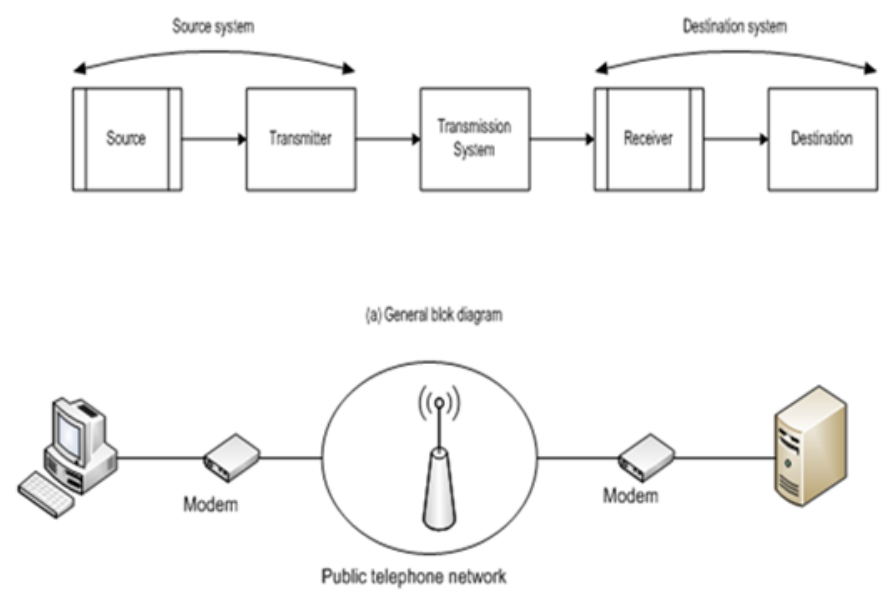

Fig. 1. Simple communication model.

\section{B. Data Communications Network}

Often, it is impractical when two communication devices are connected directly, from end to end. The following are examples of possibilities that occur:

- If the devices are part of each other that are far apart, for example being at a distance of thousands of kilometers, it will certainly cost very much to connect and connect.
- There are a series of devices, each of which requires a network to connect to each other at different times. For example, all telephones in the world and all terminals and computers are owned by the same company. Except in certain cases, for example for a limited number of tools, it is not practical to have a cable to connect each part.

\section{NVIS HF (High Frequency) Radio Communication System}

Propagation on HF NVIS radio communication, especially on the sending antenna, has a basic mechanism consisting of three, namely: Reflection (reflection), Refraction (Refraction), Diffraction, Scattering High Frequency (HF) Near Vertical Incident Skywave (NVIS) is a radio wave whose wavelengths range from 10 to 100 meters, and work at frequencies between 3 to $30 \mathrm{MHz}$ radio signals in the HF NVIS band, which emit with an angle of emission (Take off or Elevation Angle) which is almost perpendicular (near vertical), so that the signal reflected by the ionospheres layer falls back to the area that is about $0-400 \mathrm{~km}$ from the origin emission. Refers to the radio propagation mode which involves the use of an antenna with a very high angle, approaching or reaching 90 degrees (straight up), together with the selection of frequencies just below the critical frequency, to establish reliable communication over a radius of 0-200 miles or more, give or take 100 miles [8][11].

The propagation mode on the HF NVIS radio is the path through which radio waves travel from the transmitter to the receiver. This path is many and varied, so it needs to be "directed", so that the greatest energy from the radio waves emitted will fall on the position of the opponent of the communication (receiver).

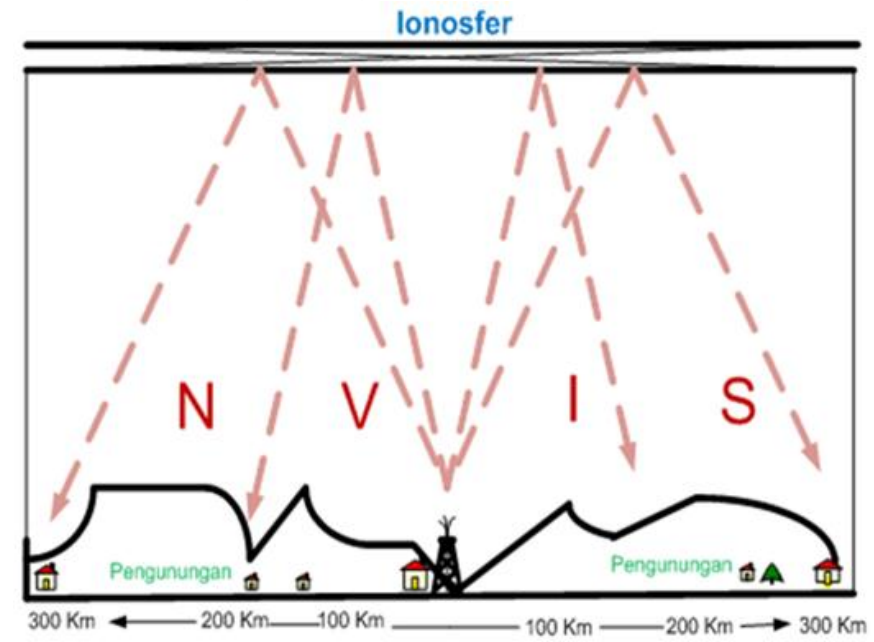

Fig. 2. Radio HF NVIS

\section{Measurement Simulation}

In the International Telecommunication Union (ITU-R) software, otherwise known as Recommendation ITU-R P.533, the Method for Prediction of the Performance of HF Circuit discusses methods for predicting frequency availability, received signal levels and predictive reliability of a digital modulation and Analogous to High Frequency (HF) communication. 
To manage data from this program by entering latitude and longitude positions for the transmitter system and on the receiving system, in $\mathrm{ddd}^{\circ} \mathrm{mm}$ 'ss.ss format "Latitude and longitude positions are changed into this format because as input for the ITURHFProp program. This ITURHFProp program is by using a command prompt (CMD). Before operating the ITURHFProp program, first, find out the format for program execution. The format used in the command prompt is as follows:

\section{ITURHFProp [Options] Input File] [Output File]}

In the ITURHFProp() software, there are two subprograms, namely P533 () and ITURHFProp(). For the P533 sub-program () it functions to calculate each High-Frequency communication parameter that appears in ITU-R. Recommendation P.533-12. It is expected that this program can be used for the implementation of the ITU-R recommendation P.533-12 and simplify the calculation if some parameters are unknown.

In addition to input the desired parameters this program must perform data processing, there are four data sources called from outside the program to set the path Data structure and run P533() including [8]

- Ionospheres data: this data is in the /Ion Map directory, in this directory contains the monthly median parameters foF2 and M (3000) F2 at each latitude and longitude location with a 1.5-degree stage for variations in sunspot number ( $\mathrm{SSN}$ ) values from low to high. Data in these files is obtained from the method in REC533 () which refers to equation (3) of ITU-R recommendation P.1293.

- Atmospheric Data: this file contains the original spherical harmonic coefficients for the parameters foF2 and $\mathrm{M}$ (3000) F2 which are related to the noise in the atmospheric layer, layer thickness, MUF statistical value and others for a particular month. For all this data, there are some data that are not updated.

- Variable MUF: in this software, there is a file "P1239 - 2 Decile Factors.txt". this file will be read by the program to get the deal factor that is related to the MUF variable. This data can be seen in ITU-R recommendations P.1239.

- Variable MUF: in this software, there is a file "P1239 - 2 Decile Factors.txt". this file will be read by the program to get the deal factor that is related to the MUF variable. This data can be seen in ITU-R recommendations P.1239.

- Antenna Data: the path data structure requires an antenna pattern on the transmitter and receiver side if implemented in a case except when choosing an isotropic type. Antenna data in this program consists of 30 degrees azimuth and elevation angle of 91 degrees. This data can be found from NEC or type 13 antenna data from VOACAP software.

\section{RESEARCH METHODS}

The methodology used in this study is literature review and simulation of data obtained in related institutions using the software ITURHFProp(), a program is by using a command prompt (CMD) [9].

\section{A. Research Steps}

The research step scheme is the beginning of the system planning stage and the application that will be created. This design scheme is based on the flow of research work.

There are 6 stages in this study, with a systematic approach starting with the literature review on the online database library, then determining location determination, creating a simulation program with MATLAB software, then synchronizing it with the ITURHFProp() program, after the success is continued at the data collection stage and the final step is reporting. Following is the flow of research work done in the form of a flow chart that shown in Fig. 3 below.

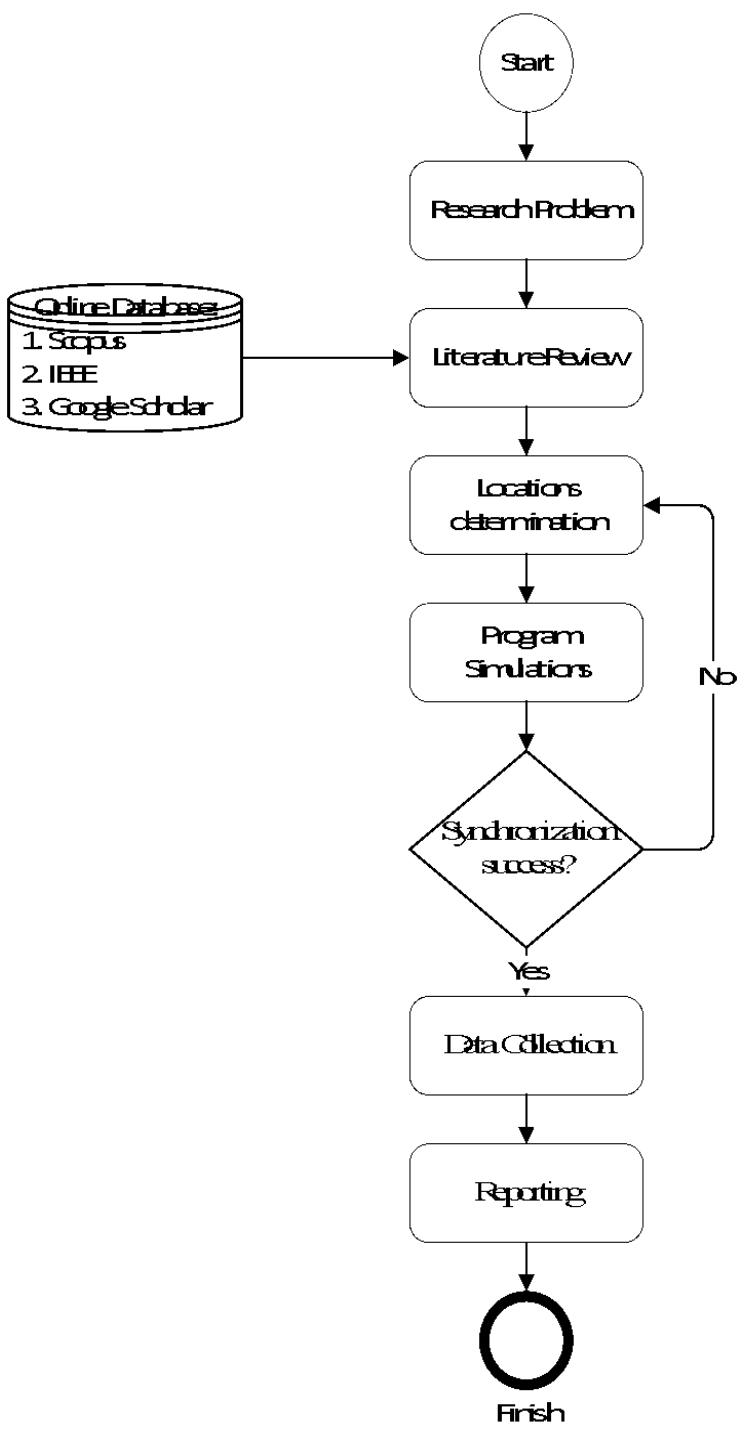

Fig. 3. Research steps

1) Literature review: This stage it is an activity to search and study literature that supports research. The literature studied relates to the usage of HF NVIS Radio as an Alternative for Data Communication in natural disaster 
Communication Systems on the islands of North Maluku. Literature is obtained from various sources including scientific journals, research results, and browsing on online databases like Scopus, IEEE and Google Scholar.

2) Location Determination: the determination of location, used in forest areas, mountains and remote areas, in this study simulated for locations that occur natural disasters so that the possibility of infrastructure cannot be used.

3) Program Simulation: this stage a program simulation is carried out to obtain the results of HF NVIS radio communication data, the simulation that will be used is the program, ITURHFProp, MATLAB R2008b and Microsoft Office Excel.

4) Synchronization: with ITURHFProp data, and calculate the budget link data from the measurement location between the transmitter and receiver. If successful synchronization occured goes straight to the next stage if No, returns to the location determination stage.

5) Data Collection: the process of collecting data using Microsoft Office Excel to compare the distance of the transmitting and receiving delivery location and the delay in HF NVIS radio communication signals reflected the ionosphere is composed of 3 (three) layers, namely: layers D, $\mathrm{E}$ and $\mathrm{F}$ which arranged from the bottom up. the $\mathrm{F}$ layer is divided into two, namely the F1 and F2 layers. This layer has a height that varies with the earth's surface depending on solar radiation, radiation from the sun that has the highest intensity during the day. While at night is the minimum. When there is no solar radiation, many of the ions rejoin into molecules.

6) Reporting: this stage a report on research results will be written according to what is obtained during the research process.

\section{B. Research Tools}

In conducting this research, there are several specifications of research tools that must be met. The specification of the research tool means the minimum standard of tools used as the main container for making the system to carry out research. Tool specifications used in this study are computers (PCs) or laptops with sufficient specifications to run programming languages.

In this study, we used laptops and PCs with Intel Core i3 specifications and Windows 10 operating systems. While the memory used was 4 GB RAM, with a 500 GB hard drive and $2.50 \mathrm{GHz}$ speed.

\section{RESULT AND DISCUSSIONS}

\section{A. Location of measurement}

North Maluku Province is one of the archipelagic provinces, which has a wider water area compared to the mainland. The characteristics of the region are island groups, in Halmahera land, mountains, coastal areas, and dominant sea crossings. That allows communication is very important to convey information when the network infrastructure cannot be used, the NVIS HF radio can be utilized.
From the NVIS HF radio communication method, the propagation mode is needed by setting the coordinate point of the transmitter location and the location of the receiver. For this simulation the transmitter is at the location of the teak village campus III Khairun University Ternate City North Maluku with a point coordinate 0 degrees 46'35.75"U and 127 degrees 22'23.92 blocked by mountains. While the location of the recipient is located on islands that are difficult to reach the signal.

\section{B. HF NVIS Radio Frequency}

HF NVIS (Near Vertical Incident Skywave) radio communication is able to overcome the skip zone so that it does not affect the quality of the beam, whether it is in water, swamps, beaches, surrounded by puddles (floods), grasslands, dense forests, mountain slopes and so on.

In this measurement simulation, the frequency used for $\mathrm{HF}$ NVIS radio is low frequency, namely 3 to 10 based on the DECISION OF GENERAL ORARI CHAIRMAN Number: KEP065 / KU / 2009 concerning the distribution and use of amateur radio frequency band segments (BANDPLAN) that allow frequency allocation for amateur radio for the $20 \mathrm{~m}$ band enforcement level (YB). Then the frequency used for this simulation is $3.5 \mathrm{MHz} 7 \mathrm{MHz}$ and $10 \mathrm{MHz}$, which is free and can be used by anyone.

Usually used to conduct a scientific experiment as a hobby by forming an organization independently so that it can communicate with each other, but does not rule out the possibility for some frequencies to be used to experience interference.

\section{Simulation of Measurement Data}

1) Calculation of the Default Link: Link Budget is a power budget estimate that needs to be taken into account to ensure that the acceptance level is well received. Link budget calculations have an important role to play in the design of the NVIS HF radio communication network to achieve optimum and efficient results in terms of both technical reliability and cost. Each transmission will lose power at 30 meters of cable.

The following parameters are used to calculate the link budget. Parameters Link budget calculation is as follows:

$$
P_{R X}=P_{T X}+G_{T X}-L_{T X}-L_{L F S}+G_{R x}-L_{R X}
$$

2) Free Space Loss (FSL): When radio signals propagate in the air they will experience damping from the air. The amount of attenuation that occurs can be calculated empirically.

$$
L_{(d b)}=32.44+20 \log D+20 \log f
$$

where:

- The distance between the two antennas is D and the transmission frequency used is $\mathrm{f}$.

- $\mathrm{D}$ in Kilometer units and $\mathrm{f}$ in Megahertz units 


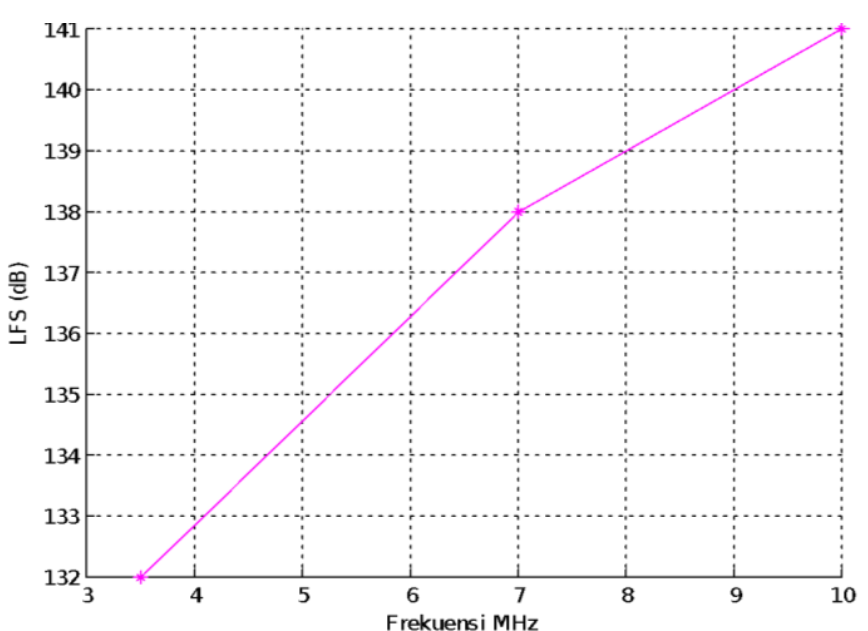

Fig. 4. The result of FSL (Free Space Loss) calculation

From Fig. 4 it can be seen that the FSL (Free Space Loss) graph is at a low frequency at a frequency of $3.5 \mathrm{MHz}$ that the calculation result obtained is $132 \mathrm{~dB}$ while the $7 \mathrm{MHz}$. From equation 2 , it is calculated by using the frequency used in the frequency of the HF NVIS Radio that is the frequency of 3.5 $\mathrm{MHz}, 7 \mathrm{MHz}$ and $10 \mathrm{MHz}$ with the distance used is $300 \mathrm{~km}$, the results are obtained as shown in table 1.

Frequency is $138 \mathrm{~dB}$, and then at $10 \mathrm{MHz}$ the frequency is $141 \mathrm{~dB}$. It shows that the greater the frequency, the higher the free space loss is used. So that for a distance of $300 \mathrm{~km}$ it is very easy to reach the islands in North Maluku.

From the results of FSL (Free Space Loss) calculations it can be calculated the receiver power (Received Power) which is known to the power of the sender (Transmitter output power) is $0.82 \mathrm{~dB}$ while the Transmitter antenna Gain is $3 \mathrm{dBi}$ Transmitter Losses (coax, connectors ...) $40 \mathrm{dBi}$ and Gain Receiver antenna $3 \mathrm{dBi}$ Receiver Losses (coax, connectors) $1.8 \mathrm{~dB}$ using equation 2 then the results can be seen in table I below.

TABLE I. BUNGDET LinK FREQUENCY CALCULATION RESUlTS AND DISTANCE 300 KM LE STYLES

\begin{tabular}{|c|c|c|c|c|c|c|c|}
\hline $\begin{array}{c}\text { Frequency } \\
(\mathbf{M H z})\end{array}$ & $\begin{array}{c}\boldsymbol{P}_{\boldsymbol{R}} \\
(\mathbf{d B m})\end{array}$ & $\begin{array}{c}\boldsymbol{P}_{T X} \\
(\mathbf{d B i})\end{array}$ & $\begin{array}{c}\boldsymbol{G}_{T X} \\
(\mathbf{d B})\end{array}$ & $\begin{array}{c}\boldsymbol{L}_{T X} \\
(\mathbf{d B})\end{array}$ & $\begin{array}{c}\boldsymbol{L}_{L F S} \\
(\mathbf{d B})\end{array}$ & $\begin{array}{c}\boldsymbol{G}_{R X} \\
(\mathbf{d B i})\end{array}$ & $\begin{array}{c}\boldsymbol{L}_{R X} \\
(\mathbf{d B})\end{array}$ \\
\hline 3.5 & -89.4837 & 40 & 3 & 0.82 & 132.863 & 3 & 1.8 \\
\hline 7 & -95.5043 & 40 & 3 & 0.82 & 132.884 & 3 & 1.8 \\
\hline 10 & -98.6024 & 40 & 3 & 0.82 & 141.982 & 3 & 1.8 \\
\hline
\end{tabular}

3) Simulation of ITURHFProp application data: To manage data from this program that is by entering latitude and longitude positions for the transmitter system and the receiving system, in $\mathrm{ddd}^{\circ} \mathrm{mm}$ 'ss.ss format "Latitude and longitude positions are changed to notepad++ format because they are input for the ITURHFProp program. The following is the display format of the HF NVIS radio data.

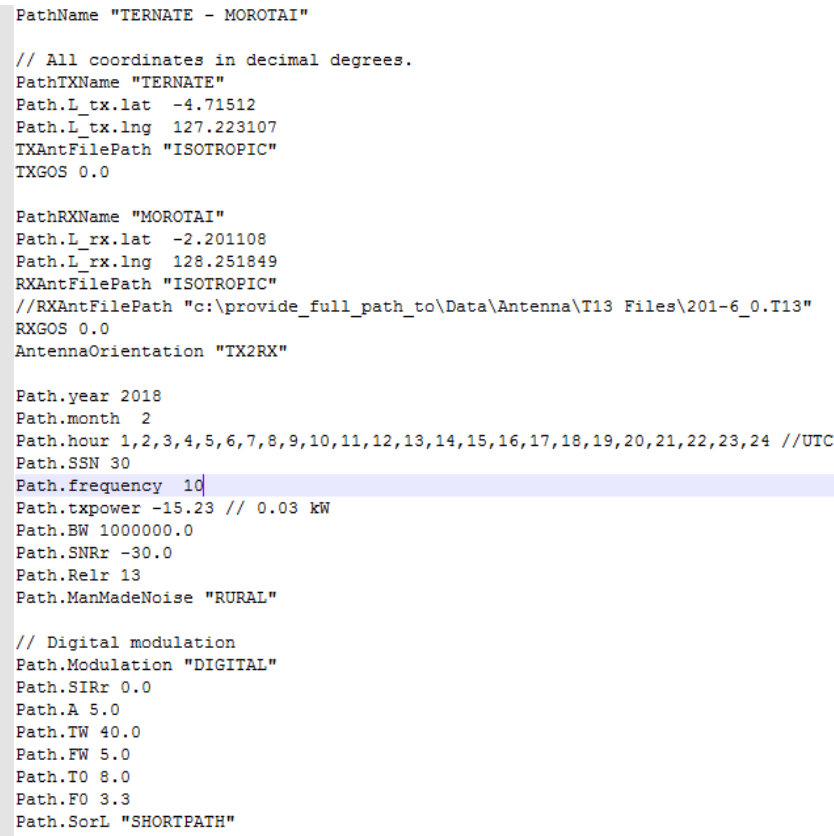

Fig. 5. Data input format in notepad ++

This ITURHFProp program is by using a command prompt (CMD). Before operating the ITURHFProp program, first, find out the format for program execution. The format used in the command prompt is as follows: including:

For the "Options" menu there are three options

ITURHFProp [Options] Input File] [OutputFile]

- $\quad$ s Silent Mode $=$ menu for displaying if a message occurs in an error during running programs.

- $\mathrm{h}$ Help = menu to bring up help

- $\quad \mathrm{v}$ Version = displays versions of the ITURHFProp () and P533 () programs.

For the "Input File" menu, it is the file name with the *.in extension as the name of the input file to be processed.

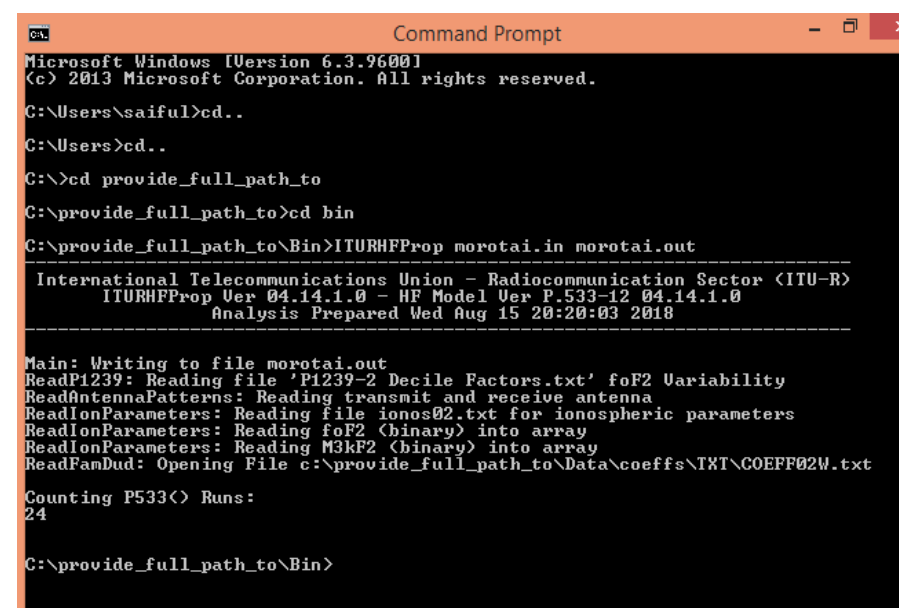

Fig. 6. Program ITURHFProp() 
After inputting parameters in Fig.6. such as latitude and longitude positions and frequencies of $3.5 \mathrm{MHz} 7$ and 10 $\mathrm{MHz}$, the year of the month, the Output Results after running are shown as in Fig. 7.

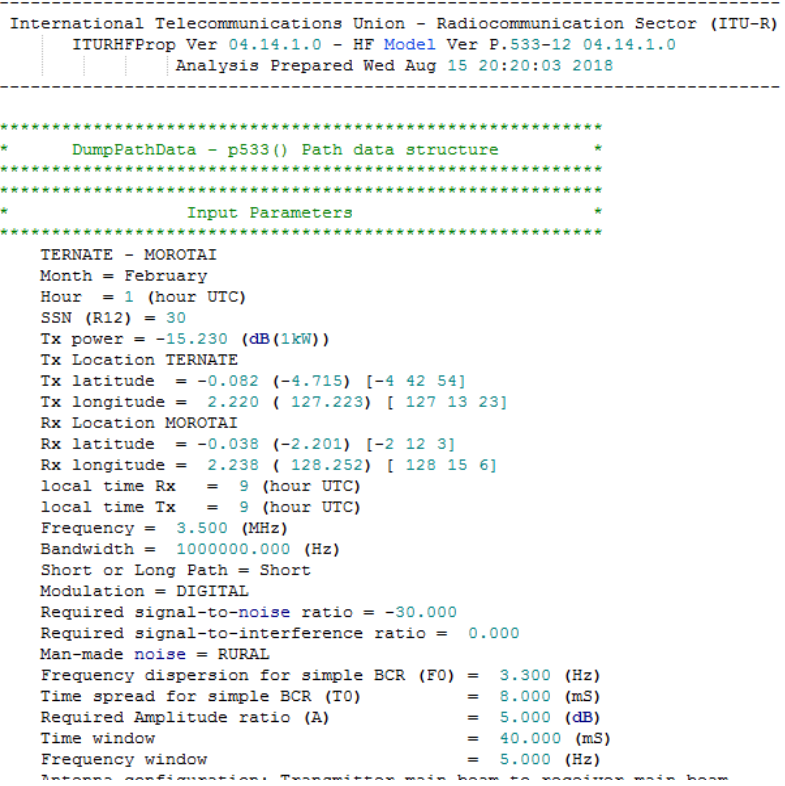

Fig. 7. Output results after running

4) The Results of Simulation and Calculation Data Measurement: From the results obtained is the distance between TERNATE and MOROTAI is $301,963 \mathrm{Km}$ with the power obtained each frequency produces the power received, can be seen in Table II below.

TABLE II. BUNGDET RECORDING POWER RECIPIENT DATA SIMULATION (RECEIVED POWER) AT A DISTANCE OF $300 \mathrm{KM}$

\begin{tabular}{|c|c|c|}
\hline $\begin{array}{c}\text { Frequency } \\
(\mathbf{M H z})\end{array}$ & $\begin{array}{c}\text { Simulation Pax } \\
(\mathbf{d B m})\end{array}$ & $\begin{array}{c}\text { Counting Pax } \\
(\mathbf{d B m})\end{array}$ \\
\hline 3.5 & -99.907 & -89.4837 \\
\hline 7 & -105.600 & -95.5043 \\
\hline 10 & -117.000 & -98.6042 \\
\hline
\end{tabular}

Table II shows that the higher the frequency used, the lower the power received, as calculated on the bungdet link by using system 1 .

The results of simulation data and the results of the calculation of the data link bungdet not too different from the results of calculations on the frequency of $10 \mathrm{MHz}$ is -98 , 6024 while on the results of simulation data the result is 117.00 this result is greater than calculations are caused by the assumed time varying from morning, afternoon, evening and night to produce greater power than calculations.

\section{CONCLUSION AND SUGGESTIONS}

The conclusion that can be drawn from the previous chapters is.
- The HF NVIS radio communication system can be used to send messages even in mountains and trees.

- The results of ITURHFProp program data can be used for verification with actual measurements.

- The ITURHFProp program simulation data is not much different from the results of manual calculations, thus indicating that the higher the frequency used, the lower the power received.

- The greater the frequency, the higher the free space loss is used.

- This study is the initial stage for developing alternative technologies for communication models in natural disaster situations or in rural areas on remote islands such as North Maluku Archipelago.

Some suggestions that can be given for the Use of $\mathrm{HF}$ NVIS Radio as an Alternative Facility in the Outer Islands of North Maluku are as follows:

- Need to try with other data sources.

- Need to take actual measurements from a closer distance.

- Need to do measurement analysis from every time.

\section{ACKNOWLEDGEMENT}

Alhamdulillahirabil'alamin, and thank you very much for the support and sponsorship of the Faculty of Engineering, Universitas Khairun, Ternate. And thanks to the smart city and e-government research group who have been matching this research at Universitas Khairun.

\section{REFERENCES}

[1] I. Jaya, "Pemodelan Arima Untuk Kanal HF link Banda AcehSurabaya," unpublished.

[2] B. Sutrisno, "Antena untuk NVIS, Materi Diseminasi Aplikasi MSILRI, Data GPS dan Ionosonda pada system komunikasi NVIS dan pengukuran GPS single frekuensi," unpublished.

[3] S. Suharti, "Komunikasi Radio High Frequency Jarak Dekat," Maj. Sains dan Teknol. Dirdirgantara, vol. 6, no.1, March 2011.

[4] U. Murat and M.R. Heidarpour, "Cooperative communication techniques for future-generation HF radios," IEEE Commun. Mag., vol. 50, pp. 56-63, 2012.

[5] J.D. Parson, The Mobile Radio Propagation Channel, New York: John Wiley \& Sons, Inc, 1992.

[6] B. Setiyanto, Dasar Dasar Telekomunikasi, Yogyakarta: Sakti, 2010.

[7] V.O. Shevchenko, Y.L. Maksimenko, Y.A. Maznichenko, and A.S. Mikryukov, "Frequency selection for HF long-haul radiocommunication in emergency situations," IEEE Cat. No.04EX843, pp. 252-253, September 2004 [14th International Crimean Conference "Microwave and Telecommunication Technology, 2004].

[8] M.L. Namara, The Ionosphere: Communications, Surveillance, and Direction Finding, Florida: Krieger Publishing Company, 1991.

[9] Sutoyo and A. Affandi, "Pemodelan Kanal HF Untuk Implementasi OFDM pada band Maritim," JAVA J. of Electr. and Electron. Eng., vol. 10, no.1, April 2012. 